Paolo Formenti Jeronimo Graf Arnoldo Santos Kenneth E. Gard

Kate Faltesek Alexander B. Adams

David J. Dries

John J. Marini

\section{Erratum to: Non-pulmonary factors strongly influence the stress index}

Published online: 19 February 2011

Erratum to: Intensive Care Med

(C) Copyright jointly held by Springer and ESICM 2011

\section{DOI 10.1007/s00134-011-2133-4}

The online version of the original article can be found under doi:10.1007/s00134-011-2133-4.

P. Formenti

Dipartimento di Anestesiologia, Terapia Intensiva e Scienze

Dermatologiche, Università delgi Studi, Milan, Italy

J. Graf

Unidad de Cuidados Intensivos Adultos,

Clinica Alemana de Santiago, Santiago, Chile

\section{A. Santos}

Department of Intensive Care Medicine,

Fundación Jiménez Díaz-UTE, Madrid, Spain

K. E. Gard - K. Faltesek - A. B. Adams - D. J. Dries ·

J. J. Marini (®)

Pulmonary Research, Regions Hospital/Healthpartners,

640 Jackson St., St. Paul, MN 55101, USA

e-mail: Alex.B.Adams@Healthpartners.com

Owing to an oversight on the part of the authors, the third author's name was given incorrectly. His correct name is Arnoldo Santos. 